\title{
Underwater microscope for measuring spatial and temporal changes in bed-sediment grain size
}

\author{
David M. Rubin ${ }^{\mathrm{a}, *}$, Henry Chezar ${ }^{\mathrm{b}}$, Jodi N. Harney ${ }^{\mathrm{a}, 1}$, David J. Topping ${ }^{\mathrm{c}}$, \\ Theodore S. Melis ${ }^{c}$, Christopher R. Sherwood ${ }^{\mathrm{d}}$ \\ ${ }^{\text {a }}$ U.S. Geological Survey, 400 Natural Bridges Dr., Santa Cruz, CA 95060, USA \\ ${ }^{\mathrm{b}}$ U.S. Geological Survey, 345 Middlefield Rd., Menlo Park, CA 94025, USA \\ ${ }^{\mathrm{c}}$ U.S. Geological Survey, 2255 N. Gemini Dr., Flagstaff, AZ 86001, USA \\ ${ }^{\mathrm{d}}$ U.S. Geological Survey, 384 Woods Hole Road, Woods Hole, MA 02543, USA
}

\begin{abstract}
For more than a century, studies of sedimentology and sediment transport have measured bed-sediment grain size by collecting samples and transporting them back to the laboratory for grain-size analysis. This process is slow and expensive. Moreover, most sampling systems are not selective enough to sample only the surficial grains that interact with the flow; samples typically include sediment from at least a few centimeters beneath the bed surface. New hardware and software are available for in situ measurement of grain size. The new technology permits rapid measurement of surficial bed sediment. Here we describe several systems we have deployed by boat, by hand, and by tripod in rivers, oceans, and on beaches.
\end{abstract}

Published by Elsevier B.V.

Keywords: Underwater microscope; Bed sediment; Grain size; In situ measurement; Colorado river; Adriatic Sea

\section{Introduction}

Grain-size analysis is fundamental to sedimentology, but despite technological advances in laboratory instruments, grain-size analysis is still time consuming and expensive. Moreover, most sampling systems are poorly adapted to measuring grain size of surficial sediment the grains that interact with the flow. Previous work (Rubin, 2004) has described algorithms for grain-size

\footnotetext{
* Corresponding author. Tel.: +1 8314274736.

E-mail addresses: drubin@usgs.gov (D.M. Rubin), hchezar@usgs.gov (H. Chezar), jodi@coastalandoceans.com (J.N. Harney), dtopping@usgs.gov (D.J. Topping), tmelis@usgs.gov (T.S. Melis), csherwood@usgs.gov (C.R. Sherwood).

${ }^{1}$ Present address: Coastal and Ocean Resources, 9865 Saanich Rd. Ste. 214, Sidney, BC Canada V8L 5 Y8.
}

analysis from digital images. This paper describes new hardware for rapidly mapping grain size of surficial sediment and for tracking changes through time in grain size at a single location on the bed.

\section{Methods}

\subsection{Traditional approach}

Most traditional approaches to grain-size analysis of sand-size sediment on the bed require collecting a sample using a dredge or other sampling device and then transporting the sample to a laboratory where it is analyzed using mechanical sieving (Krumbein and Pettijohn, 1938), settling through a column of water (Gibbs, 1972; Syvitski et al., 1991), or laser diffraction 
(Agrawal et al., 1991). Although laser diffraction and settling can be applied in situ to suspended sediment, in situ techniques have not been applied to bed sediment. Sampling of surficial bed sediment (the part interacting with the flow) is particularly difficult and typically involves sampling of sediment by adhesion to a greased plate and then using solvent to remove the grease prior to laboratory grain-size analysis.

\subsection{Digital image software}

Grain size of surficial bed sediment can be determined from digital images using several approaches summarized by Rubin (2004). We use an autocorrelation algorithm that is based on the idea that the degree to which nearby pixels in an image are correlated varies with grain size; nearby pixels in images of coarse grains are more highly correlated than in images of finer grains. This approach to grain-size analysis is extremely rapid. A trained student or laboratory technician can download and process up to 100 samples per hour. Although grain size calculated from images agrees relatively well with grain size measured by sieving or point counts of grains in the images, the main advantages of the photographic approach are high speed, low cost, and ability to sample surficial sediment.

The full data flow requires the following sequence of steps:

(1) Collect digital images of bed sediment in the field.

(2) Make point counts of a representative subset of these images to determine known grain sizes (for calibration); this requires perhaps a dozen images that span the range of grain sizes present in the field area.

(3) Determine spatial autocorrelation curve for the calibration images selected for step 2 .

(4) Prepare a calibration matrix relating the autocorrelation curve for each calibration image (from step 3) to the grain size measured from point counts (step 2).

(5) Measure autocorrelation curve of each sample, and convert to grain size, using calibration matrix determined in step 4.

Details, examples, the approach for reconstructing full grain-size distributions, and Matlab ${ }^{\mathbb{B}}$ code are given by Rubin (2004) and Barnard et al. (in press).

In performing this work, it is crucial to observe several quality-control requirements:

(1) Care must be used to prepare and test calibration curves. This step is crucial, because errors in calibration produce proportional errors in all subsequent grain-size analyses.

(2) Hardware must be assembled in the same way for all data collection. This includes, using the same camera settings, particularly zoom, focus, f-stop, and image-file format. Viewing windows must be replaced when they become scratched. Illumination angle must remain constant, although light intensity is not critical.

(3) It is useful to prepare a sample of uniform-size sand for quality-control tests (to verify that the hardware is configured in the same manner). Similar quality control can be accomplished by performing point counts on a small subset of processed images.

\subsection{Underwater microscope hardware}

Digital images of bed sediment can be collected by a digital camera or video camera placed on the bed by hand, lowered by winch or by hand from a boat, or using self-contained tripod-mounted systems that lower a camera to the bed at pre-set time intervals. In all cases, hardware can be simplified and image quality can be improved by following the following design guidelines:

(1) The housing is designed with a window that rests on the bed. This allows photography even in water as turbid as the Colorado River at flood stage, because the optical path is through air within the housing rather than through water (Fig. 1).

(2) The camera is pre-focused to the outside surface of the viewing window of the housing. This ensures sharp focus and maintains a constant scale from image to image.

(3) A light ring of lights is contained within the housing to insure uniform illumination.

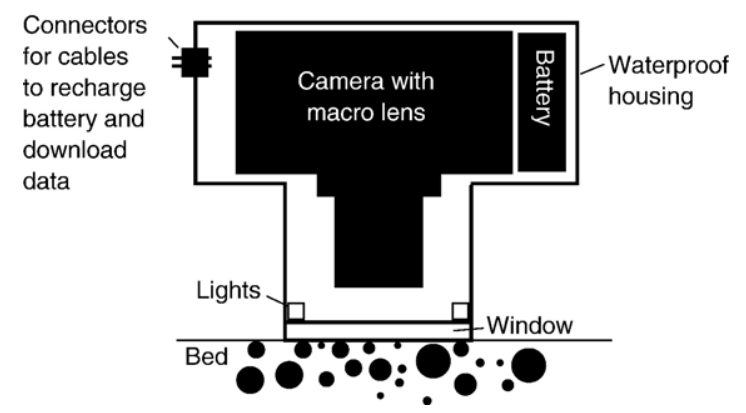

Fig. 1. Diagram illustrating the important design requirements of underwater microscope: camera housing rests on the bed; camera is pre-focused to the distance to the bed (outside surface of the window of the housing); housing contains lights that insure uniform illumination. 
We have constructed and employed eight systems based on these specifications (Chezar, 2001; Chezar and Rubin, 2004), several of which are described below. The first was fabricated by inserting a plumbing inspection video camera inside a 50-kg wrecking ball (Fig. 2a). We constructed this system to map spatial and temporal variability of grain size of sand on the bed of the Colorado River in the Grand Canyon; previous work had shown that changes in grain size on the bed are as important as changes in flow in regulating transport down the river (Rubin and Topping, 2001). Analog images from the underwater video are recorded digitally
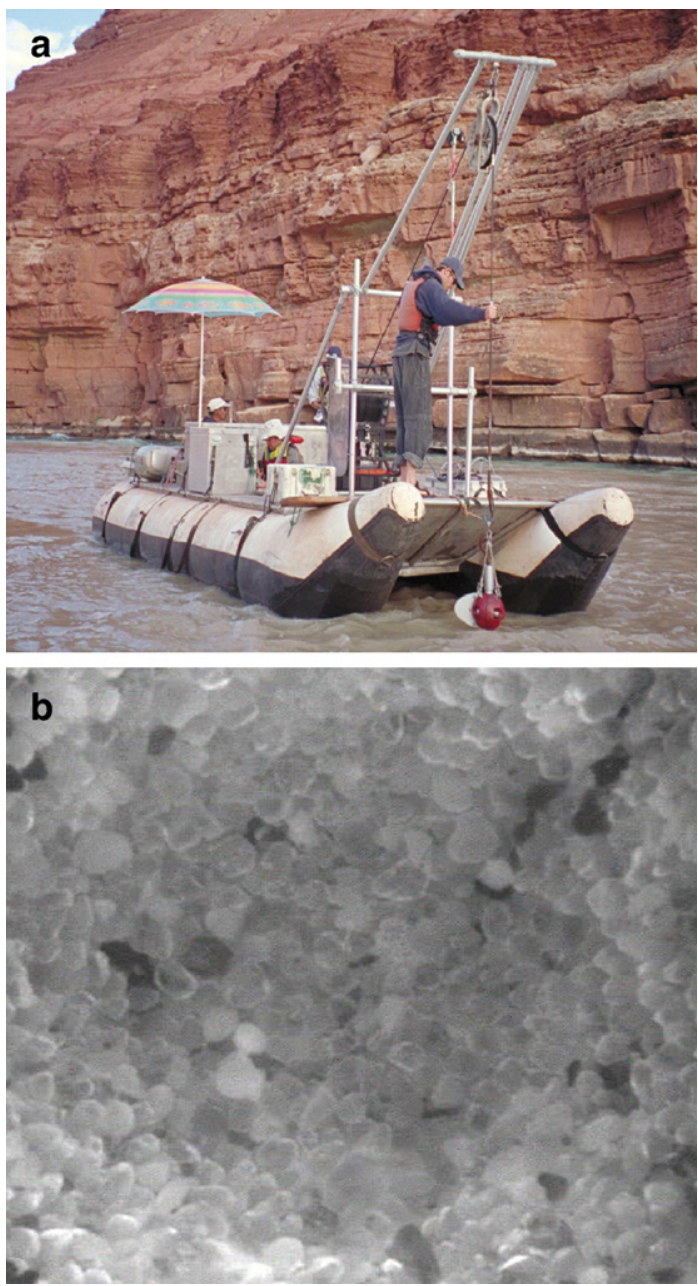

Fig. 2. First version of underwater microscope ("flying eyeball") consisting of a plumbing inspection video camera inside a wrecking ball. (a) View of boat showing frame, winch, and wrecking ball; the low-resolution analog images are recorded continuously on a digital video recorder. (b) Sample image from the system in panel a, cropped to show the region of the image used for grain-size analysis; image is approximately $1 \mathrm{~cm}$ across. on deck, and selected images (such as Fig. 2b) are used for grain-size analysis in the office. This hardware is capable of collecting hundreds of images per day. Although the images have relatively low resolution (standard video resolution of less than 1 megapixel), they are nevertheless adequate to determine mean grain size of sediment coarser than very fine sand in a $1-\mathrm{cm}^{2}$ area of the bed surface.

The wrecking-ball hardware was designed to sink to the bed of the Colorado River at flood stage and is much too heavy for deployment by hand (for mapping grain size on beaches). For this latter purpose, we placed a 5megapixel digital camera with macro lens into an underwater housing that was modified to accommodate a light ring and that was lengthened to the predetermined focal distance (Fig. 3a). The resulting system is light, compact, waterproof, and easy to operate (Fig. 3b). Depending on the camera and model of macro lens, the area being photographed is typically $\sim 2 \mathrm{~cm}$ across, and pixel size is on the order of $10 \mu \mathrm{m}$.

We developed another kind of grain-size microscope for marine use. It includes both a low-resolution video camera and 5-megapixel digital still camera. The video camera gives a standard underwater-video view, and the still camera gives a microscopic view of grains on the bed. The optical devices and electronics are housed in an underwater case that functions as one of the three legs of a tripod (Fig. 4), to insure that the camera is oriented perpendicular to the bed. An ideal system would include a computer or video monitor on deck so that the user can watch video images in real time as the device is lowered to the bed and also can view microscopic images seen by the digital camera after it reaches the bed; this microscopic image can either be a low-resolution video output that many digital cameras can output or a high-resolution image visible over USB cable and electronic components to extend the range of the USB signal. When the user is satisfied with the area of the bed being viewed, they would trigger the camera to store a high-resolution microscopic image either in camera memory or on a shipboard computer. Because digital camera technology and computer interfaces are changing so rapidly, any components we specify now will likely be outdated by the time this report is published.

All of the systems described above were designed to map grain size spatially, but grain size also varies through time at a point. Although even the crudest sediment transport models incorporate the effects of bed-sediment grain size on transport, no instruments have been developed previously to monitor temporal changes in bed sediment. Marine tripods routinely contain sophisticated instruments (worth a small 

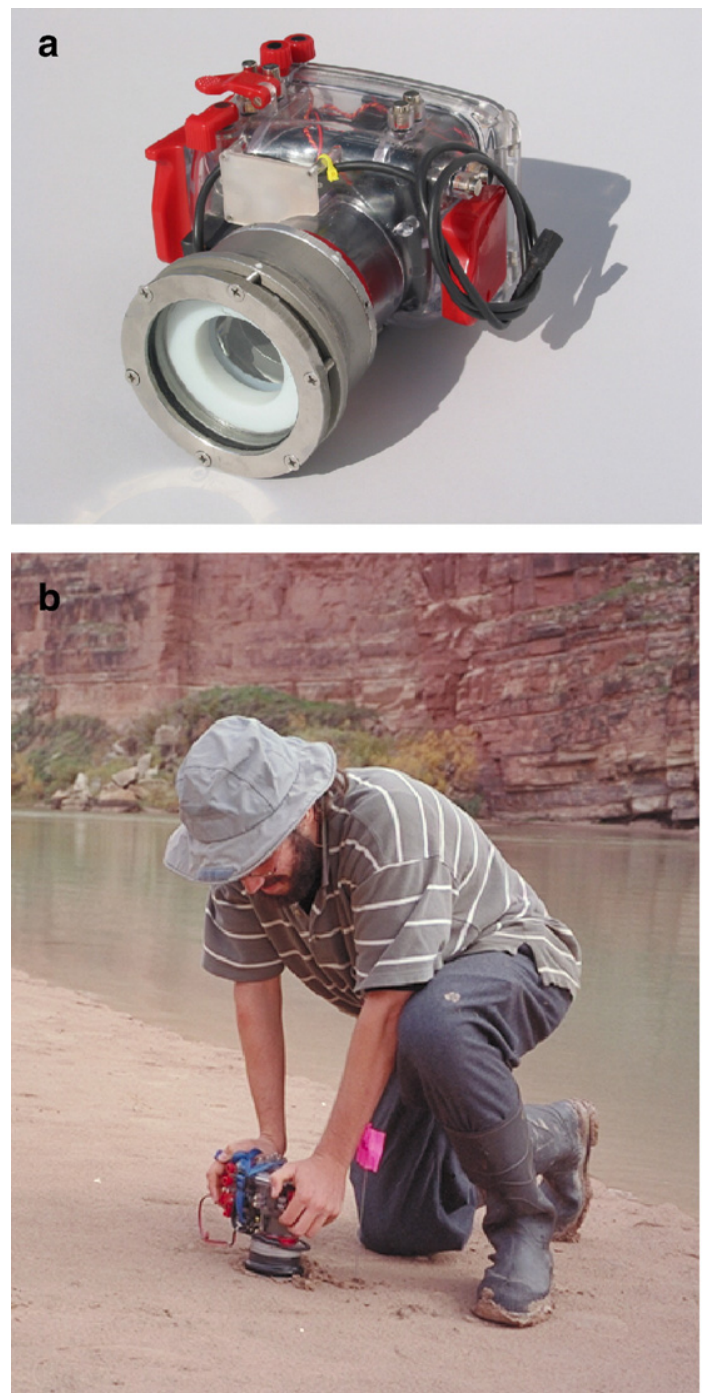

Fig. 3. Lightweight underwater microscope for hand-held use on beaches or by divers in shallow water. (a) Closeup of camera and housing; design follows requirements specified in Fig. 1. (b) Camera in use.

fortune) that are capable of measuring flow velocity and suspended sediment at frequencies up to $100 \mathrm{~Hz}$. In contrast, grain size of bed sediment might be measured only at the beginning and end of a deployment (by a grab sample or two). To address this deficiency, we have assembled and tested several autonomous bed-sediment microscopes. The best design we have tested consists of a bed-sediment camera, electronic controller, hydraulicpiston drive system, and bottom-sensing switch (Fig. 5a). An image from the previous autonomous system illustrates the exceptional resolution of a 5megapixel image of sand grains, shell fragments, and biological pellets on the bed (Fig. $5 b$ ).

\section{Examples}

\subsection{Colorado River bar sediment}

In preparation for the 2004 experimental restoration flood in Grand Canyon (Topping et al., 2006), we used the camera illustrated in Fig. 3 to collect several thousand images of sediment on the surface and $1 \mathrm{~cm}$ below the surface on emergent sand bars along the Colorado River. At several dozen locations, we retained for sieve analysis the 1-cm thickness of sand located vertically between the two images. The results are instructive for testing the accuracy of the digital grainsize analysis as well as understanding processes that are active on the bar surfaces.

Grain sizes determined by analysis of the images collected $1 \mathrm{~cm}$ beneath the bar surface are in good agreement with results obtained by sieving (Fig. 6A). The correlation between results determined by the two methods is 0.88 , but more importantly, the regression line is very close to the line of perfect agreement. This latter result is a more important test, because we would expect to find differences between the grains photographed in a single horizontal section and the grains sampled from the overlying centimeter of sand (Barnard et al., in press).

Unlike results for the subsurface sediment images, images of surface sediment do not agree with the sieve results for the top centimeter of sediment (Fig. 6B); the surface sediment is systematically coarser by $30-50 \%$ $(\sim 0.04$ to $0.10 \mathrm{~mm})$. We interpret this difference to arise from real trends in grain size with depth, rather than differences in technology used for grain-size analysis.

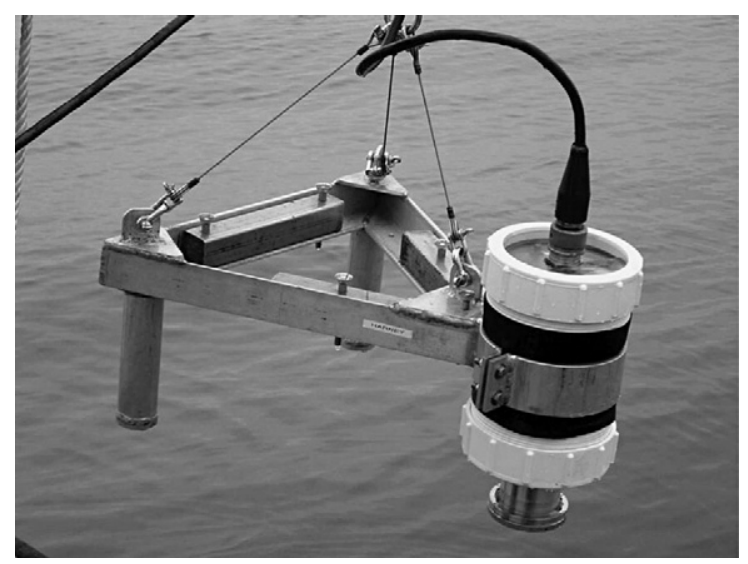

Fig. 4. Integrated camera and video system for marine grain-size mapping. Video camera, digital still camera with macro lens, and electronics are contained within a single underwater housing that also functions as one of the three legs of the tripod. 
a

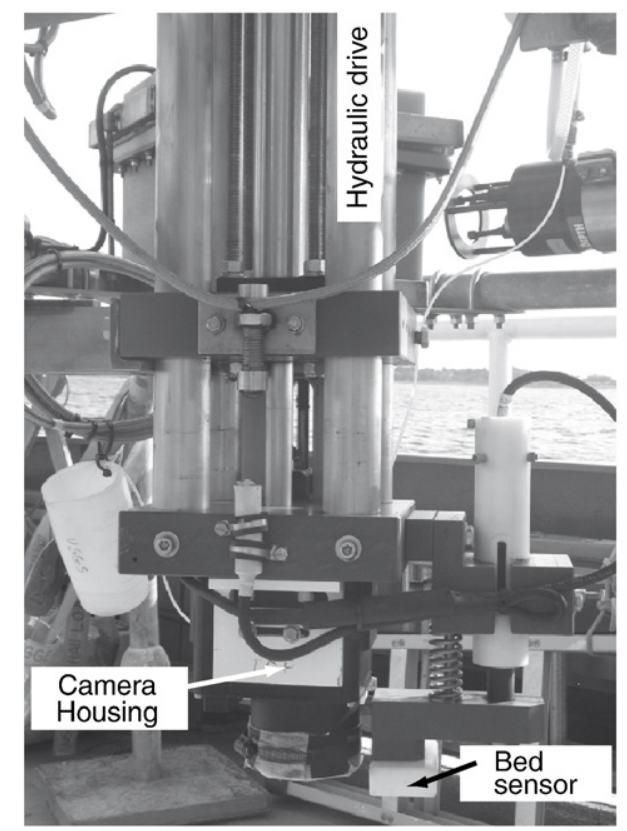

b

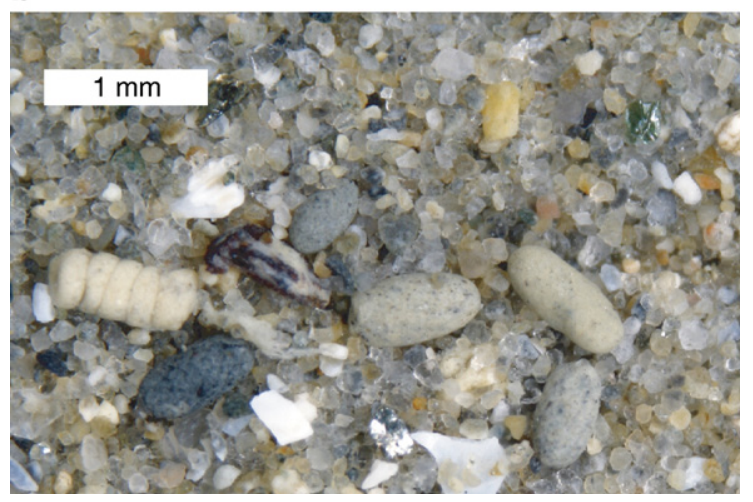

Fig. 5. Autonomous bed-sediment microscope for tripod deployments. (a) Photo of instrument mounted on tripod. (b) Sample image from 10-m depth in the Adriatic Sea.

Three observations support this interpretation: (1) image analysis worked accurately at a depth of $1 \mathrm{~cm}$ in the same sediment, (2) results of the image analysis indicate that the sediment on the surface is coarser than in the subsurface, and (3) all surface samples were from areas that had not been inundated for at least 2.5 months, during which time the surface sediment was subject to winnowing by wind. These results (grain size of the uppermost $1 \mathrm{~cm}$ of sediment finer than the bed surface and not detectably coarser than the grain size at a depth of $1 \mathrm{~cm}$ ) indicate that the depth of winnowing by wind is probably no thicker than a millimeter or two.

These results illustrate two properties resulting from the high spatial resolution of digital grain-size analysis.
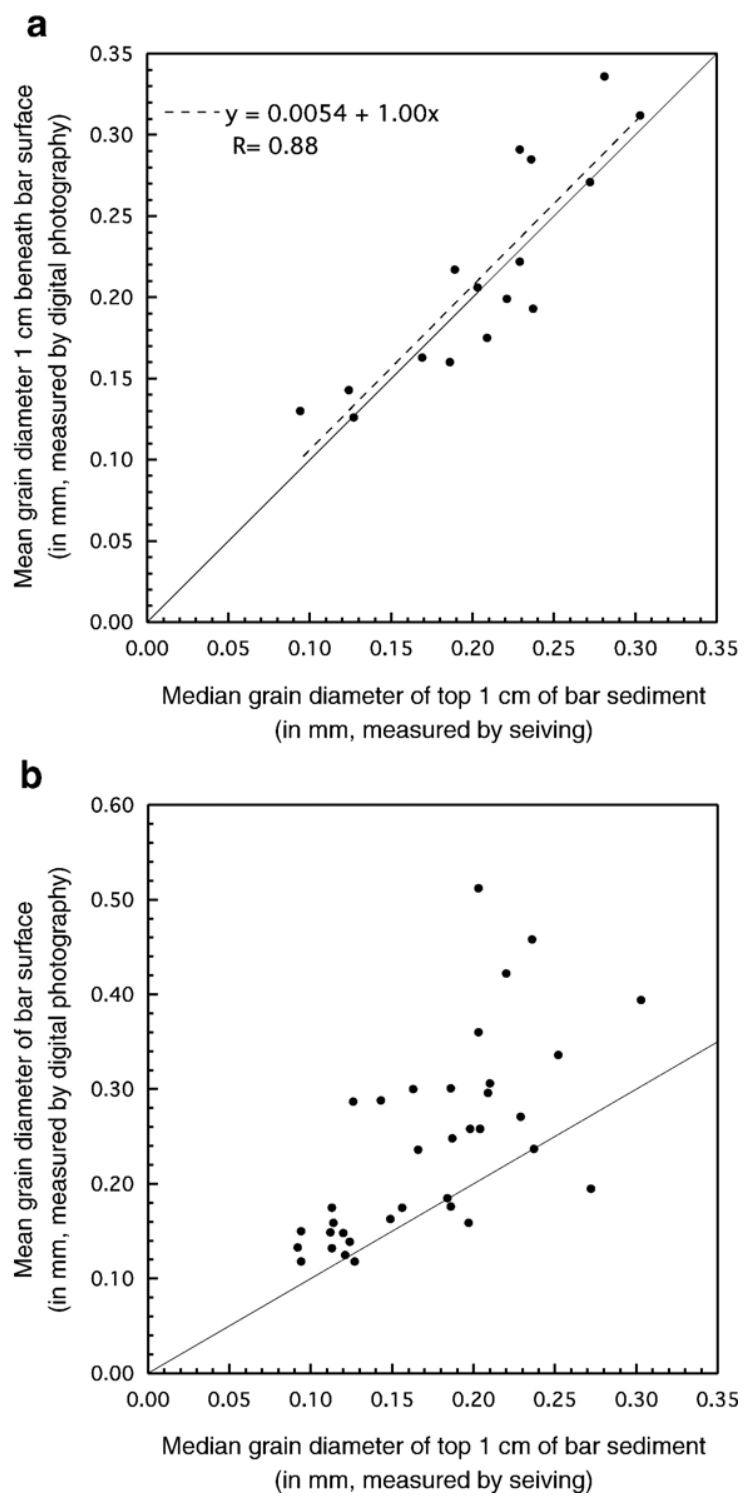

Fig. 6. Comparison of sediment grain size determined by image analysis and by sieving for samples from bars along the Colorado River in Grand Canyon. Pairs of digital images were collected at the bed surface and at a depth of $1 \mathrm{~cm}$ below the surface using the camera shown in Fig. 3. Sediment between each pair of images was collected in the field and measured by sieve analysis in the laboratory. (a) Comparison of surface sediment analyzed from digital imagery with the underlying centimeter of sediment analyzed by sieving; grain sizes determined using the two techniques are in close agreement. (b) Comparison of sediment $1 \mathrm{~cm}$ beneath the bar surface analyzed from digital imagery with the overlying sediment analyzed by sieving. Results of the two analyses differ, not because image-analysis results are faulty, but because the surface images sample of a different population of grains (surficial sediment is systematically coarser, as a result of winnowing by wind). 


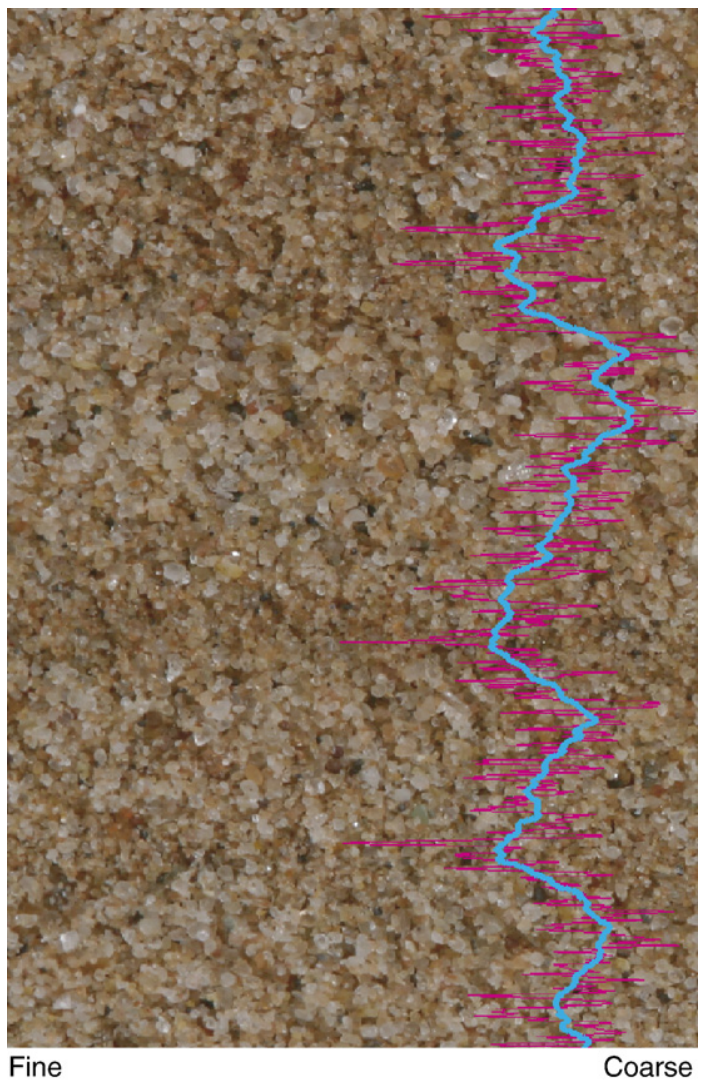

Fig. 7. Vertical profile of grain size through laminae deposited by wind ripples. Each wind ripple deposited a layer that coarsens upward (Hunter, 1977), followed by abrupt fining.

Because the grain size calculated for an image applies only to that image (or to a part of an image, as illustrated in the following section), extremely high spatial resolution is possible. The technology has the capability of documenting spatial variability in grain size on the scale of a millimeter. The disadvantage of such high resolution is the limited spatial scale of each sample. Because grain size varies spatially, nearby samples may have differing results, and multiple samples are required to characterize the grain size at a particular region of a bed or stratigraphic horizon (Barnard et al., in press).

\subsection{Vertical profiles through inversely graded wind- ripple deposits}

Digital photography also can be used to make vertical profiles in grain size though a sediment deposit - in the sidewall of a trench or in a core (Rubin, 2004). The hardware required for this purpose is much simpler than for underwater use; all that is required is a digital camera. Grain size can be measured on a smaller scale than can be sampled physically (a thousand measurements over a few centimeters), and calculations are extremely rapid (less than $10 \mathrm{~s}$ to compute the vertical grain-size profile through an image). An example of inverse grading in wind-ripple deposits is shown in Fig. 7.

\section{Conclusions}

Digital analysis of microscopic images can be used to measure grain size of bed sediment. Here we describe the hardware used for this work and some of the considerations for applying this approach. The technology is ideally suited for collecting large numbers of grain-size measurements for mapping surficial grain size of sand. Because a few days are required to learn how to use this technology, to make calibration curves, and to test the hardware and software are working properly, the technology is advantageous only for large numbers of samples (perhaps 100 samples or more). Once the calibration curves are prepared, a trained worker can process 500 samples per day. In Grand Canyon, we routinely collect several thousand images per survey. In addition to rapid data collection and processing, this approach offers high spatial resolution and convenient analysis of the uppermost layer of grains on the bed the grains that interact with the flow.

\section{Acknowledgements}

This work was supported by the Grand Canyon Monitoring and Research Center of the USGS; adaptation of instruments for autonomous tripod deployment was supported by the Office of Naval Research. Alexander Rubin collected the grain-size images from Grand Canyon, and Carissa Carter and Tristan Rhodes performed grain-size analysis using those images. Eric Grossman and Curt Storlazzi (USGS) reviewed an earlier draft of this manuscript. Use of trade names is for descriptive purposes and does not imply endorsement by the USGS.

\section{References}

Agrawal, Y.C., McCave, I.N., Riley, J.B., 1991. Laser diffraction size analysis. In: Syvitski, J.M.P. (Ed.), Principles, Methods and Application of Particle Size Analysis. Cambridge University Press, New York, pp. 119-128.

Barnard, P.L., Rubin, D.M., Harney, J.N., Mustain, N., in press. Field test comparison of an autocorrelation technique for determining grain size using a digital 'beachball' camera versus traditional methods. Sedimentary Geology.

Chezar, H., 2001. Underwater microscope system. USGS Fact Sheet 135-01. U.S. Government Printing Office, Washington, D.C., 2 pp. 
Chezar, H., Rubin, D., 2004. Underwater microscope system. U.S. Patent and Trademark Office, patent number 6,680,795, January 20, 2004, 9 pp.

Gibbs, R.J., 1972. The accuracy of particle-size analyses utilizing settling tubes. Journal of Sedimentary Petrology 42, 141-145.

Hunter, R.E., 1977. Basic types of stratification in small eolian dunes. Sedimentology 24, 361-387.

Krumbein, W.C., Pettijohn, F.J., 1938. Manual of Sediment Petrography. Appleton-Century Crofts Inc., New York. 549 pp.

Rubin, D.M., 2004. A simple autocorrelation algorithm for determining grain size from digital images of sediment. Journal of Sedimentary Research 74, 160-165.

Rubin, D.M., Topping, D.J., 2001. Quantifying the relative importance of flow regulation and grain-size regulation of suspended-sediment transport $(\alpha)$ and tracking changes in grain size on the bed $(\beta)$. Water Resources Research 37, 133-146.

Syvitski, J.P.M., Asprey, K.W., Clattenburg, D.A., 1991. Principles, design and calibration of settling tubes. In: Syvitski, J.M.P. (Ed.), Principles, Methods and Application of Particle Size Analysis. Cambridge University Press, New York, pp. 45-63.

Topping, D.J., Rubin, D.M., Schmidt, J.C., Hazel Jr., J.E., Melis, T.S., Wright, S.A., Kaplinski, M., Draut, A.E., Breedlove, M.J., 2006. Comparison of sediment-transport and bar-response results from the 1996 and 2004 controlled-flood experiments on the Colorado River in Grand Canyon. CD-ROM Proceedings of the 8th Federal Inter-Agency Sedimentation Conference, April 2-6, 2006, Reno, Nevada. ISBN: 0-9779007-1-1. 